\title{
1 Aquaponics water use and nutrient cycling in a seawater- 2 cooled controlled environment agriculture system
}

3

4

\author{
R. Lefers ${ }^{1, a}$, A. Alam ${ }^{2}$, F. Scarlett ${ }^{3}$ and T. Leiknes ${ }^{1}$
}

${ }^{1}$ King Abdullah University of Science and Technology (KAUST), Water Desalination \& Reuse Center (WDRC), Biological and Environmental Science and Engineering Division (BESE), Thuwal, Saudi Arabia; ${ }^{2}$ Edenworks Inc. and A\&A Epiphany, LLC, New York City, USA; ${ }^{3} A \& A$ Epiphany, LLC, Jeddah, Saudi Arabia

\begin{abstract}
To demonstrate the water use efficiency and nutrient cycling of an aquaponics system in combination with a seawater based evaporative cooling system, a pilot-scale aquaponics unit was installed and operated for one year inside a controlled environment agriculture building cooled by the evaporation of seawater on the campus of King Abdullah University of Science and Technology in Thuwal, Saudi Arabia. Results collected from the operation included crop water use, water quality parameters, dissolved ion concentrations, outdoor/indoor climate data and crop output. Seawater-based evaporative cooling did not provide adequate indoor temperatures for the cultivation of lettuce during the hot and humid summer season. However, the combined aquaponics with seawater evaporative cooling was effective for fall, winter, and spring cultivation with a mixed crop of lettuce and tomatoes. Opposite to the vegetable production cycle, higher water temperature in the summer favored the production of Sabaki tilapia during the warm summer season rather than the cool winter season. Because of this dichotomy, the system showed promise for management and nutrient balancing on an annual basis rather than on seasonal or daily basis. From a fresh water use perspective, the average daily fresh water use by plants totaled only $4.6 \mathrm{~L}$ day $^{-1} \mathrm{~m}^{-2}$ or $19 \mathrm{~L} \mathrm{~kg}^{-1}$ of crop harvested during the peak winter/spring growing season. Results demonstrated that an aquaponics system in combination with seawater-based evaporative cooling is capable of saving $~ 90 \%$ of fresh water as compared with traditional forms of agriculture in the region.
\end{abstract}

Keywords: Aquaponics, controlled environment agriculture, evaporative cooling

\section{INTRODUCTION}

Food and water security are two very important and interconnected challenges facing the world today, with around $70 \%$ of all fresh water use worldwide for irrigation. Therefore, it is imperative to develop systems and methods of food production that are capable of producing more food with less fresh water (Lefers et al., 2016)

Recirculating aquaponics combines hydroponics (growing plants in water, without soil) and aquaculture (farming fish or other aquatic organisms) to produce food (Suhl et al., 2016). In this system, waste of aquatic organism is broken down by bacteria into dissolved nutrients that plants utilize in a hydroponic unit as depicted in Figure 1. Because the only water losses in an aquaponics system are due to plant transpiration and evaporation from open system surfaces (evapotranspiration), it is considered a "green" food production system (Reyes Lastiri et al., 2016). In traditional aquaculture, effluents from intensive fish

\footnotetext{
a E-mail: ryan.lefers@kaust.edu.sa
} 
production systems containing high levels of nutrients may be discharged to the environment, leading to pollution of local waters. However, in an aquaponics system, the nutrient-rich aquaculture effluents provide most of the nutrients required by plants if the optimum ratio between daily feed input and plant growing area is maintained (Rakocy, 1999). Aquaponics systems work by balancing nutrient generation from fish waste with nutrient uptake by plants to achieve proper water quality (Al-Hafedh et al., 2008). This use of the nutrients by plants purifies the water, which is continuously cycled to and from the fish and crops when using a recirculating setup. Plants in aquaponics grow rapidly using the natural dissolved nutrients from the fish. Nutrient levels in water from the fish tanks can be maintained at concentrations similar to hydroponic nutrient solutions where synthetic fertilizers are applied. There is a nominal daily water addition (typically $<3 \%$ of total volume) in these systems to make up for evapotranspirational losses (Al-Hafedh et al., 2008). The benefits of aquaponics systems include recovery of waste nutrients by the plants, elimination of environmental pollution, low water use and low operational costs (Bosma et al., 2017). The daily supply of fish feed provides the original source of nutrients that sustains both the sub-systems (aquaculture for the fish and horticulture for the plants). This efficient use of resources provides a secondary vegetable crop in addition to the fish at no extra material input, thereby improving the profit potential of the operation and the food output. Pesticide and chemical usage is naturally limited by the biology of the multiple organisms included in the system, therefore, aquaponics can be regarded as a safe and clean form of agriculture (Rokocy, 1999). In case the aquaponics system is not operated as organic farming, permissible pesticides could be used by temporarily decoupling the aquaponics system (disconnecting aquaculture and horticulture components).

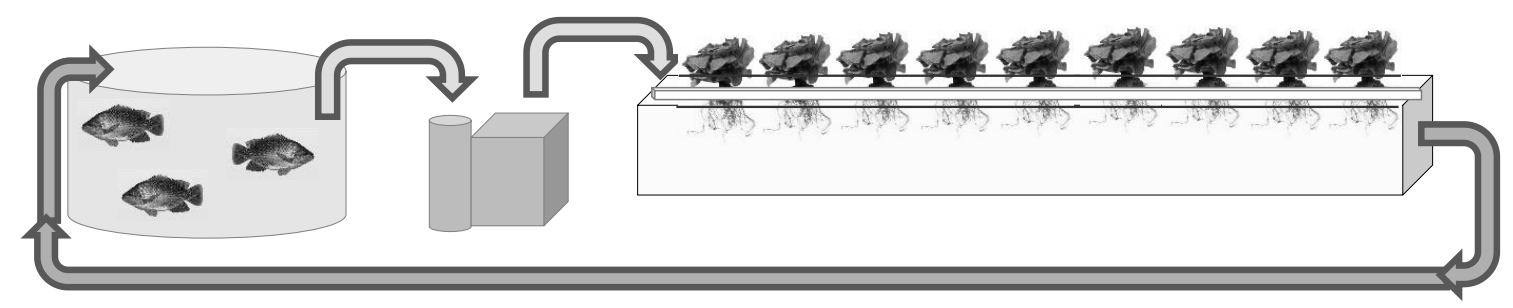

Figure 1. Water flow in recirculating aquaponics. Water moves from fish tanks to water treatment to plant roots and back again.

When aquaponics is applied in Controlled Environment Agriculture (CEA), the indoor climate can be adjusted to allow year-round production. Significantly more food output per unit land area is possible with such a system than in traditional agriculture. The combination of higher food output with a lower water footprint per kg of food produced makes CEA based aquaponics a promising technology for solving food and water shortages in challenging climates worldwide, including Saudi Arabia. Based upon these advantages, a pilot-scale aquaponics unit was installed for evaluation of water use and productivity at the King Abdullah University of Science and Technology (KAUST).

One of the major factors that allows CEA to produce large amounts of food is the control of temperatures within the system at optimal levels (generally, in the range of 20-25 ${ }^{\circ} \mathrm{C}$ for most crops). In hot climates, this means extensive cooling for greenhouses inundated with solar thermal heat loads. The most common practice for cooling of greenhouses worldwide is evaporative cooling (Kittas et al., 2001). Traditional evaporative cooling consumes large amounts of fresh water in the process. Up to $80 \%$ of the total greenhouse fresh water use can come from evaporative cooling (Lefers et al., 2016; Sabeh, 2007). 
Efforts to build and operate greenhouses that utilize seawater for cooling have demonstrated the feasibility of the approach in appropriate climates (Dawoud et al., 2006; Mahmoudi et al., 2010; Zamen et al., 2013). Greenhouses using seawater for cooling were constructed in the Canary Islands (Paton and Davies, 1996), UAE (Davies and Paton, 2004), Oman (Ghaffour et al., 2011), Australia (Davies et al., 2008), Qatar and Jordan (http://saharaforestproject.com). However, evaporative cooling processes face the fundamental limitation of poor evaporative cooling performance when the outdoor ambient air is already near saturation. In humid regions similar to the Red Sea coast near Jeddah, this means that internal greenhouse conditions may exceed $30^{\circ} \mathrm{C}$ during the hot and very humid months (July through September), which reduces product quality for some crops and prevents year-round cultivation of other crops (Abu-Hamdeh and Almitani, 2016).

In the present study, we experimentally validated the total fresh water use of a combined aquaponics with seawater cooling system for CEA. In addition, we experimentally validated the potential of the combined technologies for producing crops year-round in the humid coastal climate near to Jeddah, Saudi Arabia. Water quality and climatic parameters were collected and analyzed, with a discussion of results in the following sections.

\section{MATERIALS AND METHODS}

A pilot-scale aquaponics system was setup within a CEA system at KAUST with an indoor climate cooled by evaporative cooling using seawater. The installed aquaponics system was an F5 system from Nelson and Pade, Inc. (www.aquaponics.com). The system included a fish tank with a volume of approximately 400 liters, a clarifier, a netting tank, a degas/base addition tank and two raft-style hydroponics trays with a total plant growing area of $3 \mathrm{~m}^{2}$ and 90 plant sites $\left(\sim 30\right.$ plant sites $\left.\mathrm{m}^{-2}\right)$. The water flow rate in the system was adjusted such that the hydraulic retention time in the clarifier was approximately 20 minutes. Sabaki tilapia (Oreochromis spilurus) were cultured in the fish tank from April 2016-May 2017, fed a commercial pelleted diet with $32 \%$ proteins at $2 \%$ body weight daily. A feed ratio was targeted between 56 and $80 \mathrm{~g}$ feed per square meter of plant growing surface daily. A mix of vegetables was cultured over the course of the experiment, including lettuce, basil, tomatoes, cucumbers, parsley and other herbs.

Water use was monitored over the course of the experiment by tracking the amount of make-up water added to the system. Water quality parameters were monitored over the course of the experiment in the field and in the lab. Field water quality parameters, including water temperature, dissolved oxygen, $\mathrm{pH}$, and conductivity were monitored on a minimum weekly basis via field probes. Water samples were collected for laboratory analysis on a monthly or bi-monthly basis. Cations tracked over the course of the experiment included boron, sodium, magnesium, aluminum, potassium, calcium, manganese, iron, copper, zinc and molybdenum. Cations were quantified using an Agilent $7500 \mathrm{cx}$ inductively coupled plasma mass spectrometry (ICPMS) machine. Anions tracked included fluoride, chloride, nitrite, sulfate, bromide, nitrate and phosphate. Anions were quantified using a Dionex ICS 1600 ion chromatography machine.

Seawater was evaporated using a pad and fan type evaporative cooling system to cool and purify incoming outdoor air. The use of saline water in place of fresh water in evaporative cooling systems, particularly in water scarce regions, offers a potential solution for greatly improving the sustainability of controlled environment agriculture (CEA) systems. However, the use of saline water in industry-standard cellulose pad systems can cause premature clogging of the porous medium, leading to system failure and may also need frequent replacement of the pads. Therefore, to replace standard pads, porous pozzolan rock bricks were used for evaporative cooling because these pozzolan bricks show impressive resistance to saline water and salt buildup (Lefers et al. 2018). Salts in the seawater were concentrated over time as the water evaporated from the system. Therefore, 
to prevent salt buildup in the system, concentrated seawater ( $50-60 \%$ of input volume) was removed and replaced with fresh seawater on a daily basis. A Vantage Pro2 weather station by Davis Instruments captured climate data (including indoor/outdoor air temperature and humidity and outdoor wind and solar radiation) at 30-minute intervals.

\section{RESULTS AND DISCUSSION Seawater evaporative cooler performance}

The seawater evaporative cooling system was effective during the cooler parts of the fall, winter, and spring seasons; but was ineffective in maintaining temperatures low enough for the cultivation of cool-season crops like lettuce during the hotter summer months. Figure 2 shows the average monthly outdoor and indoor temperatures at the CEA system. In general, the average indoor temperatures were $26^{\circ} \mathrm{C}$ or above from April 2016 through October 2016, and then fell below $26^{\circ} \mathrm{C}$ from November 2016 through April 2017.

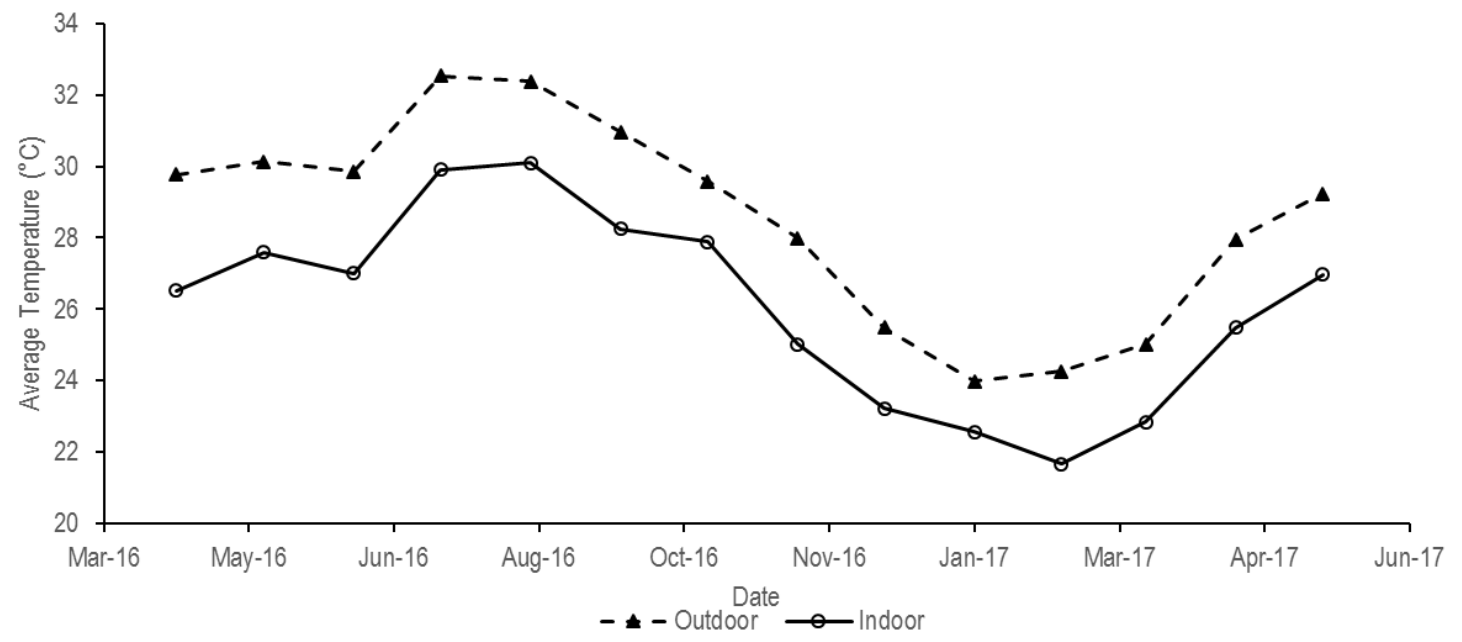

Figure 2. Average monthly air temperatures during the experiment, day and night included.

\section{Hydroponics performance and water consumption}

Fully contained aquaponics systems in CEA have the potential to both conserve water and protect plants from a harsh outdoor environment. (Konig et al., 2016). In the experimental system, lettuce was cultivated throughout the course of the study and combined crops of tomatoes and lettuce were cultivated from October 2016-May 2017. Lettuce was successfully grown during the initial spring growing season from April-June 2016. During the hot summer months of July-September 2016, no lettuce was harvested. High indoor temperatures and insect pests greatly inhibited plant growth and prevented successful cultivation of marketable crops during the summer season. In the fall season, from October through December 2017, combined crops of tomatoes and lettuce were cultivated. The tomatoes began to bear fruit during the winter season (January-April). Crops grown during this season were high quality and marketable, as indoor temperatures were favorable (average $\sim 23{ }^{\circ} \mathrm{C}$ ) and no insect pests were observed. While water use in the aquaponics system averaged $2.6 \mathrm{~L}_{\text {day-1 }}^{-1} \mathrm{~m}^{-2}$ over the one year of system operation, the aquaponics system water use in the winter season averaged $4.6 \mathrm{~L} \mathrm{day}^{-1} \mathrm{~m}^{-2}$ when crop performance was at its peak. The average water use by lettuce and tomatoes during the spring season was $\sim 19 \mathrm{~L} \mathrm{~kg}^{-1}$ of produce harvested. Unlike traditional CEA systems where fresh water is evaporated to cool the indoor environment, the only fresh water consumed in the seawater-cooled CEA system was the irrigation water. When compared to the world average fresh water use of $\sim 237 \mathrm{~L} \mathrm{~kg}^{-1}$ for lettuce and $214 \mathrm{~L} \mathrm{~kg}^{-1}$ for tomatoes in traditional agriculture (Mekonnen and Hoekstra, 2011), a saving of 90\% of water was obtained by growing crops in the seawater-cooled aquaponics system $\left(19 \mathrm{~L} \mathrm{~kg}^{-1} \mathrm{vs} . \sim 225 \mathrm{~L} \mathrm{~kg}^{-1}\right)$. 


\section{Aquaculture performance}

Fish weights were recorded at the beginning and at the end of the experiment. Forty Sabaki tilapia were stocked into the system with an initial average weight of $\sim 10$ grams fish1 , providing a stocking density of approximately $1 \mathrm{~kg} \mathrm{~m}^{-3}$ of fish tank water. By the end of the experiment, the tilapia had grown to reach an average size of $\sim 300$ grams $^{-1} \mathrm{ish}^{-1}$, therefore the final stocking density of the fish was approximately $\sim 32 \mathrm{~kg} \mathrm{~m}^{-3}$ of fish tank water. While not measured directly, it was noted visually that tilapia growth was faster during the summer as compared to the winter months. This was expected as the water temperatures were closer to the favorable range $\left(28-32^{\circ} \mathrm{C}\right)$ during the summer.

\section{Water quality}

Figure 3 shows the average values of water temperature, dissolved oxygen, $\mathrm{pH}$, and conductivity collected over the course of the experiment as measured via the field meter. The dissolved oxygen sensor failed in August 2016 and was not replaced, therefore dissolved oxygen values were not recorded after this point. In October 2016, a maintenance error led to the loss of approximately $1 / 3$ of the aquaponics system water, which was replaced by fresh water from the KAUST seawater reverse osmosis treatment plant.
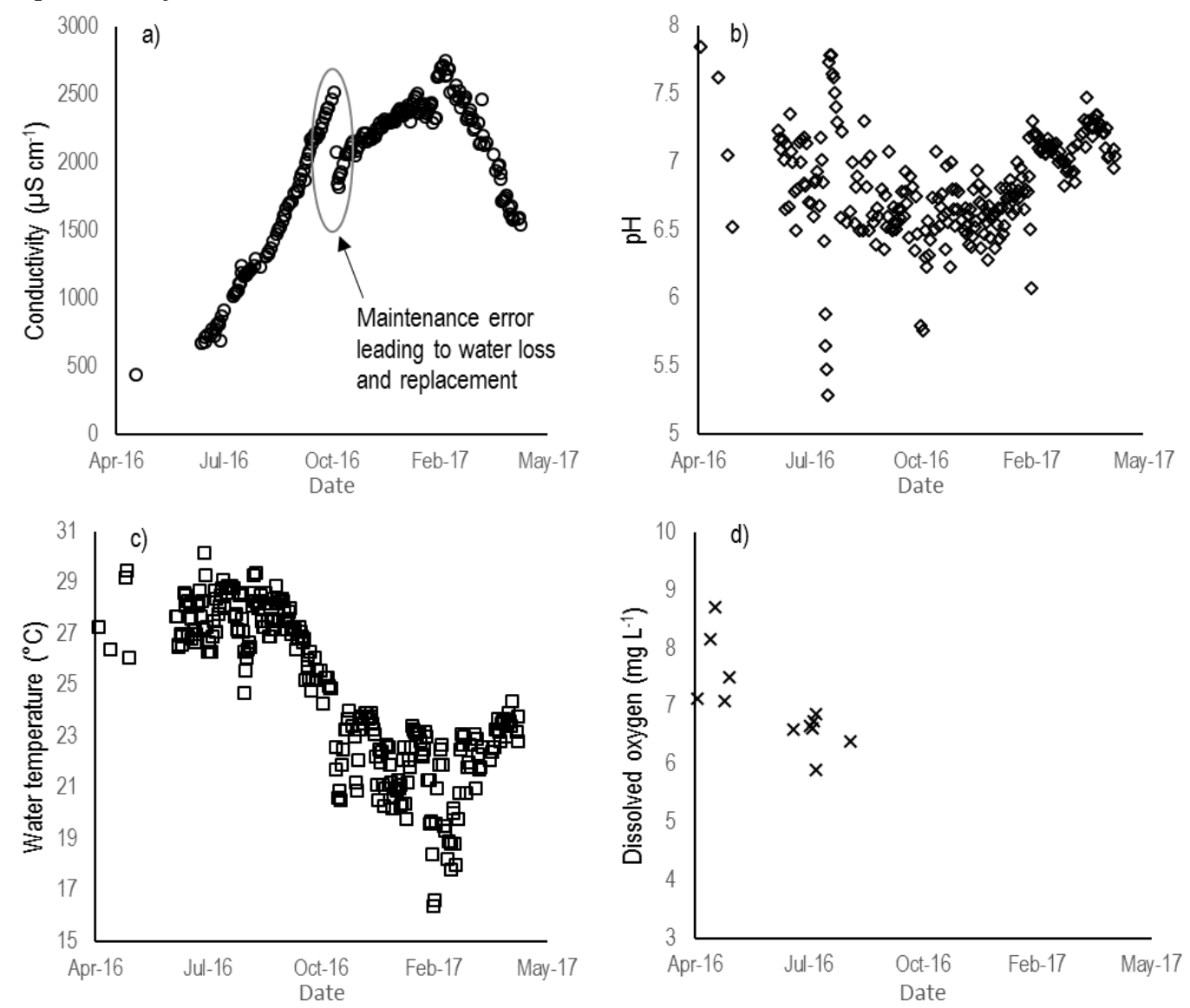

Figure 3. Water quality: a) conductivity, b) pH, c) temperature, d) dissolved oxygen.

Conductivity results showed a generally increasing trend through February of 2017, with the exception of the October 2016 water loss and replacement event. Conductivity increased as ion concentrations increased in the system water due to nutrient addition from fish waste, base addition, and concentration of any salts present due to water loss via evapotranspiration. When the addition of these ions was higher than the removal/use by the plants, the conductivity went up. In February 2017 during the peak of the winter 
growing season, the total plant mass increased to the point that the plants began removing dissolved nutrient ions from the water faster than they were being added. Therefore, conductivity began to decrease from this point on until system shutdown.

$\mathrm{pH}$ levels measured over the course of the experiment varied between 5.3 and 7.9 standard units. The $\mathrm{pH}$ was modified via the addition of bases such as calcium hydroxide, potassium hydroxide, and/or calcium carbonate through February 2017 to try to keep the $\mathrm{pH}$ above 6.5. During this period, $\mathrm{pH}$ would decrease continuously, requiring based addition. From February 2017, when the plants began using more nutrients than were being added to the water from fish waste, the $\mathrm{pH}$ naturally trended up instead of down. No acids were added during this period to lower the $\mathrm{pH}$, the $\mathrm{pH}$ was allowed to rise and naturally regulate.

Water temperatures in the system during the summer period of June-August 2016 were in the range of $26-30{ }^{\circ} \mathrm{C}$. Most tilapia species suitable for food culture grow best at about $29-30^{\circ} \mathrm{C}$. (Mullins and Sink, 2015) From September 2016, the water temperatures dropped until November 2016. From December 2016-April 2017, the water temperatures generally stayed in their winter range of $20-23{ }^{\circ} \mathrm{C}$. Then, in April of 2017 the water temperature began to rise again towards the summer range.

Dissolved oxygen (DO) levels were measured through August 2016, when the oxygen sensor failed. A minimum DO concentration of $5 \mathrm{mg} \mathrm{L}^{-1}$ is required for the proper functioning of such a recirculating system and DO levels above this level are ideal for fish, plants, and microbes in the system (Mullins and Sink, 2015). During the period from system initiation in April 2016 until August 2016, dissolved oxygen levels stayed above $5 \mathrm{mg} \mathrm{L}^{-1}$, with values ranging from $\sim 5.9-8.8 \mathrm{mg} \mathrm{L}^{-1}$.

\section{Nutrient cycling}

Plants require macro- and micronutrients. Aquaponics systems provides these nutrients from the air, the source water, additives, and from the breakdown of fish waste (Mullins and Sink, 2015). Table 1 shows the ions measured over the course of the experiment. In general, nutrient levels increased but were below the target range until September/October. Plants in the system were under-stocked relative to fish biomass during the summer because of the poor growing conditions for the plants (higher than the desirable air temperature and insect pests) and the good growing conditions for the fish (water temperatures in the range $25-30{ }^{\circ} \mathrm{C}$ ). Therefore, the nutrient levels built up in the system during this time. Nutrient levels increased to a peak in January/February and then decreased until the system was shut down because plant densities were over-stocked relative to fish biomass (desirable air temperatures, mature tomato vines in addition to lettuce, no recorded insect pests for plants and lower than desirable water temperatures for the fish). Micro nutrients (FloraMicro mix, www.generalhydroponics.com) were added at various times during system operation to supplement nutrients (such as iron) that were not naturally provided from the make-up water or the fish waste.

An interesting observation from the year-long experiment in the seawater-cooled CEA system was that summer conditions favored sabaki tilapia production due to favorable water temperatures while winter conditions favored vegetable production due to favorable air temperatures. Recirculating aquaponics has always required balancing between the needs of the fish and the needs of the plants. What this is perhaps suggesting is that nutrients can be cycled on a seasonal basis in a recirculating aquaponics system. Although successful cultivation of cool-season crops like lettuce may not be possible in summer in an evaporative-cooled CEA system in a hot and humid climate, the summer season can be used to build up nutrient levels via fish cultivation for later winter time use in crop production. In such a way, the hydroponics system can "rest" during summer months while aquaculture of warm-season fish like tilapia builds the nutrient reserves in the system. By designing and 
managing the aquaponics system in the proper way, it is theorized that nutrient balancing in the system can be creatively managed with respect to both the crops and the season. It is suggested that a multi-year study be conducted to test this hypothesis in future work.

Table 1. Dissolved nutrient concentrations in aquaponics system water throughout the experiment.

\begin{tabular}{l|ccccccc}
\hline & $\begin{array}{c}\text { Target } \\
\text { range }^{1}\end{array}$ & \multicolumn{6}{c}{ Sampling date and concentrations (mg L-1) } \\
\cline { 3 - 8 } Nutrient $^{-1}$ mg L $^{-1}$ ) & $7 / 27 / 16$ & $9 / 24 / 16$ & $11 / 9 / 16$ & $1 / 19 / 17$ & $3 / 6 / 17$ & $5 / 14 / 17$ \\
\hline $\mathrm{B}$ & $0.1-1$ & 1.1 & 1.1 & 0.9 & 1.0 & 1.3 & 1.6 \\
$\mathrm{Mg}$ & $25-75$ & 6 & 13 & 9 & 9 & 9 & 5 \\
$\mathrm{~K}$ & $200-400$ & 80 & 366 & 235 & 216 & 162 & 10 \\
$\mathrm{Ca}$ & $150-400$ & 48 & 9 & 10 & 8 & 11 & 6 \\
$\mathrm{Mn}$ & $0.1-1$ & 0.0 & 0.0 & 0.1 & 0.0 & 0.0 & 0.0 \\
$\mathrm{Fe}$ & $0.5-5$ & 0.2 & 0.2 & 0.7 & 1.0 & 2.1 & 1.4 \\
$\mathrm{Cu}$ & $0.02-0.2$ & 0.01 & 0.02 & 0.09 & 0.03 & 0.09 & 0.05 \\
$\mathrm{Zn}$ & $0.02-0.2$ & 0.03 & 0.06 & 0.44 & 0.51 & 0.64 & 0.38 \\
$\mathrm{Mo}$ & $0.01-0.1$ & 0.00 & 0.00 & 0.00 & 0.01 & 0.01 & 0.00 \\
$\mathrm{NO}_{3}$ & $300-1300$ & 120 & 1000 & 550 & 800 & 470 & 360 \\
$\mathrm{PO}_{4}$ & $30-90$ & 5 & 3 & 8 & 25 & 5 & 1 \\
$\mathrm{TN}^{n}$ & $70-300$ & 25 & 220 & 120 & 180 & 100 & 80 \\
\hline
\end{tabular}

1Source for target ranges (Nelson, 2008).

253

254

255

256

257

258

259

260

261

262

263

264

265

266

267

268

269

\section{CONCLUSIONS}

An aquaponics system was implemented and evaluated to grow fresh fish and produce within a CEA system cooled by evaporation of seawater at KAUST. The system was not effective at growing plant produce during the hot summer months because of higher than desirable indoor temperatures. However, the system was effective at growing high-quality produce during the cooler winter and spring months. Opposite to the plants, the summer season was more favorable to sabaki tilapia production because of high water temperatures while the winter season had water temperatures that were cooler than desirable for tilapia. Therefore, water nutrient levels in the system tended to follow seasonal trends as well, with increasing nutrient level in the summer and decreasing nutrient levels in the winter. This nutrient cycling suggests a new type of management for aquaponics system installed in similar climates, with a proposed focus on maximizing aquaculture during summer months and maximizing hydroponics plant culture during winter months. When compared with world average fresh water use per $\mathrm{kg}$ of vegetables produced in the field, the aquaponics system installed inside of the seawater-cooled CEA system saved $\sim 90 \%$ of fresh water, with an average daily water use of $4.6 \mathrm{~L} \mathrm{day}^{-1} \mathrm{~m}-2$ or $19 \mathrm{~L} \mathrm{~kg}^{-1}$ of crop harvested during the peak winter/spring growing season.

\section{ACKNOWLEDGEMENTS}

The research reported in this publication was sponsored by King Abdullah University of Science and Technology (KAUST). The authors thank colleagues at the Water Desalination and Reuse Center (WDRC), and KAUST's Core Labs for their help, equipment and analysis.

\section{LITERATURE CITED}

Abu-Hamdeh, N.H., and Almitani, K.H. (2016). Solar liquid desiccant regeneration and nanofluids in evaporative cooling for greenhouse food production in Saudi Arabia. Solar Energy 134, 202-210.

Al-Hafedh, Y.S., Alam, A., and Beltagi, M.S. (2008). Food production and water conservation in a recirculating aquaponic system in Saudi Arabia at different ratios of fish feed to plants. Journal of the World Aquaculture Society 39, 510-520. 
Bosma, R.H., Lacambra, L., Landstra, Y., Perini, C., Poulie, J., Schwaner, M.J., and Yin, Y. (2017). The financial feasibility of producing fish and vegetables through aquaponics. Aquacultural Engineering 78, 146-154.

Davies, P., and Paton, C. (2004). The Seawater Greenhouse in the United Arab Emirates: Thermal Modelling and Evaluation of Design Options. Desalination 173, 103-111.

Davies, P.A., Hossain, A.K., Lychnos, G., and Paton, C. (2008). Energy saving and solar electricity in fan-ventilated greenhouses. Acta Hort 797, 95-101.

Dawoud, B., Zurigat, Y.H., Klitzing, B., Aldoss, T., and Theodoridis, G. (2006). On the possible techniques to cool the condenser of seawater greenhouses. Desalination 195, 119-140.

Ghaffour, N., Reddy, V.K., and Abu-Arabi, M. (2011). Technology development and application of solar energy in desalination: MEDRC contribution. Renewable and Sustainable Energy Reviews 15, 4410-4415.

Kittas, C., Bartzanas, T., and Jaffrin, A. (2001). Greenhouse evaporative cooling: measurement and data analysis. Transactions of the ASAE 44, 683-689.

Konig, B., Junge, R., Bittsanszky, A., Villarroel, M., and Komives, T. (2016). On the sustainability of aquaponics. Ecocycles 2, 26-32.

Lefers, R., Bettahalli, N.M.S., Nunes, S.P., Fedoroff, N., Davies, P.A., and Leiknes, T. (2016). Liquid desiccant dehumidification and regeneration process to meet cooling and freshwater needs of desert greenhouses. Desalination and Water Treatment 57, 23430-23442.

Lefers, R., Davies, P.A, Fedoroff, N.V., AlMadhoun, N., Tester, M.A., Leiknes, T. (2018). Proof of Concept: Pozzolan Bricks for Saline Water Evaporative Cooling in Controlled Environment Agriculture. Applied Engineering in Agriculture 34, 929-937.

Mahmoudi, H., Spahis, N., Abdul-Wahab, S.A., Sablani, S.S., and Goosen, M.F.A. (2010). Improving the performance of a Seawater Greenhouse desalination system by assessment of simulation models for different condensers. Renewable and Sustainable Energy Reviews 14, 2182-2188.

Mekonnen, M.M., and Hoekstra, A.Y. (2011). The green, blue and grey water footprint of crops and derived crop products. Hydrology and Earth System Sciences 15, 1577-1600.

Mullins, B.N., and Sink, T.D. (2015). Principles of small-scale aquaponics, Southern Regional Aquaculture Center.

Nelson, R.L. (2008). Aquaponics Food Production, Montello, WI, USA: Nelson and Pade, Inc.

Paton, C., and Davies, P. (1996). The Seawater Greenhouse for Arid Lands. Paper presented at: Mediterranean Conference on Renewable Energy Sources for Water Production, Santorini, Greece.

Reyes Lastiri, D., Slinkert, T., Cappon, H.J., Baganz, D., Staaks, G., and Keesman, K.J. (2016). Model of an aquaponic system for minimised water, energy and nitrogen requirements. Water Sci Technol 74, 30-37.

Rokocy, J.E. (1999). The status of aquaponics part 2. In Aquaculture Magazine.

Sabeh, N.C. (2007). Evaluating and Minimizing Water Use by Greenhouse Evaporative Cooling Systems in a SemiArid Climate. In Department of Agricultural and Biosystems Engineering (Tucson, Arizona: The University of Arizona).

Suhl, J., Dannehl, D., Kloas, W., Baganz, D., Jobs, S., Scheibe, G., and Schmidt, U. (2016). Advanced aquaponics: Evaluation of intensive tomato production in aquaponics vs. conventional hydroponics. Agricultural Water Management 178, 335-344.

Zamen, M., Amidpour, M., and Firoozjaei, M.R. (2013). A novel integrated system for fresh water production in greenhouse: Dynamic simulation. Desalination 322, 52-59. 